\title{
O ENSINO DE LÍNGUA ITALIANA NAS ESCOLAS PÚBLICAS DE SANTA CATARINA: REFLEXÕES A PARTIR DAS DEMANDAS DA PÓS- MODERNIDADE
}

\author{
LA ENSEÑANZA DE LENGUA ITALIANA EN LAS ESCUELAS PÚBLICAS DE SANTA \\ CATARINA/BRASIL: REFLEXIONES A PARTIR DE LAS DEMANDAS DE LA \\ POSMODERNIDAD
}
THE LEARNING OF ITALIAN IN THE PUBLIC SCHOOLS OF SANTA CATARINA/BRAZIL: REFLECTIONS FROM THE DEMANDS OF POST MODERNITY

Carla Regina Martins Valle* Universidade do Estado de Santa Catarina

RESUMO: O objetivo do presente artigo é oferecer um breve panorama atualizado sobre o ensino da língua italiana nas escolas públicas de Santa Catarina/Brasil e refletir sobre as contribuições das perspectivas linguísticas conectadas com demandas contemporâneas (teorias pós-modernas críticas, pós-coloniais, sociolinguística de terceira onda e linguística aplicada) para o ensino de línguas em contextos de imigração. Conclui-se que a oferta da língua italiana nas escolas públicas de Santa Catarina sofreu brusca redução e aponta-se a necessidade de entender os processos de identificação dos sujeitos com suas línguas de herança como ponto de partida para o planejamento de políticas para o ensino da língua.

PALAVRAS-CHAVE: Ensino de língua italiana. Políticas linguísticas críticas. Sociolinguística.

RESUMEN: El objetivo del presente artículo es ofrecer un breve panorama actualizado sobre la enseñanza de la lengua italiana en las escuelas públicas de Santa Catarina/Brasil y reflexionar sobre las contribuciones de las perspectivas lingüísticas conectadas con demandas contemporáneas (teorías post-modernas críticas, post-coloniales, sociolingüística de tercera ola y la lingüística aplicada) para la enseñanza de lenguas en contextos de inmigración. Se concluye que la oferta de la lengua italiana en las escuelas públicas de

* Pesquisadora pós-doc PNPD/CAPES junto a o Programa de Pós-graduação em Linguística da Universidade Federal de Santa Catarina e professorasubstitutada UniversidadedoEstadode Santa Catarina. E-mail: <carlavallel0@gmail.com>. 
Santa Catarina sufrió brusca reducción y se apunta la necesidad de entender los procesos de identificación de los sujetos con sus lenguas de herencia como punto de partida para la planificación de políticas para la enseñanza de la lengua.

PALABRAS CLAVE: Enseñanza de lengua italiana. Políticas lingüísticas críticas. Sociolingüística.

ABSTRACT: The aim of this paper is to offer a brief overview of the teaching of the Italian language in public schools in the state of Santa Catarina, Brazil, and to reflect on the contributions of the linguistic perspectives connected with contemporary demands (postmodern critical theories, postcolonial theories, third wave sociolinguistics, and applied linguistics) for the teaching of languages in immigration contexts. We have concluded that the provision of the Italian language in the public schools of Santa Catarina went through a sharp reduction, and it is necessary to understand the processes of identification of the subjects with their inheritance languages for the planning of policies for the teaching of language.

KEYWORDS: Italian language teaching. Critical language policy. Sociolinguistics.

\section{INTRODUÇÃO}

Historicamente o ensino de línguas estrangeiras, em especial o ensino de língua italiana, não tem recebido espaço adequado no contexto educacional público brasileiro. Grego e latim eram as línguas ensinadas no período colonial e, somente com a criação do Colégio Pedro II, em 1837, é que o espaço se abre para o ensino de línguas estrangeiras modernas, com ênfase na leitura e em exercícios de tradução e análise gramatical. Nesse período, apesar dos escassos registros, parece haver uma expansão considerável na oferta de línguas estrangeiras, obviamente para aqueles que podiam estudar. Aos alunos, durante o período do império, eram ofertadas cerca de quatro a cinco línguas, dentre elas o italiano que era facultativamente ofertado e já nesse período recebia menor prestígio que as demais línguas modernas, sendo excluído do plano educacional do Colégio Pedro II com a lei de 1870, justamente quando se fortalecem os movimentos de imigração italiana (LEFFA, 1999; FREITAS; BALTHAZAR; LUNATI, 2015).

O ensino da língua italiana passou por várias fases no Brasil. Com a chegada dos imigrantes e instaurada a diversidade dialetal por conta das várias regiões de proveniência, o ensino dos dialetos como língua materna deu-se nas escolas étnicas. Pouco depois, a busca pela unidade italiana no período fascista levou à promoção do ensino do italiano standart mesmo fora da Itália, iniciativa que acabou sendo apagada pela política de interdição de línguas da Era Vargas. No final do século XX, o ensino da língua sofreu uma expansão considerável por conta de esforço conjunto entre Brasil e Itália para a valorização da cultura italiana e da Lei de Diretrizes e Bases de 1996. Mas, atualmente, por conta da redução dos auxílios do governo italiano e da Lei 13.415 de 2017 (BRASIL, 2017) que impõe o ensino do Inglês, temos considerável queda na oferta do idioma nas escolas públicas do Brasil.

Diante dessa situação, o presente artigo objetiva oferecer um breve panorama atualizado sobre a oferta de língua italiana no Estado de Santa Catarina e refletir sobre as contribuições das perspectivas linguísticas conectadas com as demandas contemporâneas (teorias pós-modernas críticas, pós-coloniais, sociolinguística de terceira onda e linguística aplicada) para o ensino de língua estrangeira em contextos de imigração.

Com tal intuito, na próxima seção apresentamos um panorama geral e resumido de momentos distintos do ensino da língua italiana no Brasil; na terceira seção, apresentamos breve mapeamento da oferta da língua nas escolas públicas do Estado de Santa Catarina na última década; em seguida, na quarta seção, procuramos refletir sobre o ensino de italiano a partir das novas agendas das teorias linguísticas.

\section{BREVE RETROSPECTIVA DO ENSINO DE LÍNGUA ITALIANA NO BRASIL}

No século XIX cerca de 57 milhões de europeus rumaram para as Américas para fugir da fome, da miséria causada pela crise agrícola, de conflitos religiosos e de guerras em seus países de origem. No Brasil, um dos principais destinos desse enorme contingente populacional foram as províncias do Sul (entre 1875 e 1892), e os Estados do Sudeste: Rio de Janeiro, Espírito Santo e Minas Gerais. Destaque ainda maior deve-se dar para São Paulo que recebeu 56\% dos 4.100 .000 estrangeiros que chegaram no Brasil entre $1886 \mathrm{e}$ 
1934, sendo a maior parte deles provenientes da península itálica, que vieram trabalhar nas lavouras de café e na construção de ferrovias (TRENTO, 1988).

As primeiras tentativas para o ensino de língua italiana, ou melhor, dos vários dialetos que eram as línguas maternas dos imigrantes advindos da Itália que se estabeleceram no Brasil, deram-se com a criação de escolas comunitárias e étnicas. Tais iniciativas foram bastante comuns, a partir de 1870, em algumas colônias do Rio Grande do Sul, por exemplo, onde, dada a inexistência de escolas públicas, a comunidade escolhia os mais instruídos dentre os moradores para serem os professores (SCHNEIDER, 1993).

Na virada dos séculos XIX para XX, o governo italiano do período fascista, buscando construir o sentimento de unidade nacional e uma identidade italiana também fora da pátria, investiu no ensino para aqueles que vieram para o Brasil. Foram então criadas as Case d' Italia, que tinham um papel centralizador, abrigando as diversas associações locais (Lombarda, Vêneta, Trentina), com a intenção de enaltecer uma suposta etnia italiana. Nesse período, professores foram enviados da Itália para ensinar em italiano standart e foram instituídas escolas mantidas pelo governo italiano, muito comuns no Rio de Janeiro, por exemplo. Contudo, o uso dos dialetos ainda se mantinha vivo e o papel da igreja foi importante para a manutenção das línguas de origem nas colônias (GAIO, 2017).

Esse movimento de incentivo ao ensino do italiano standart, e também dos dialetos, foi bruscamente interrompido na Era Vargas, quando se instituiu o movimento nacionalista brasileiro. O Decreto-Lei de Getúlio Vargas, de 1939, proibiu o uso das línguas dos países inimigos na Segunda Guerra Mundial (Alemanha, Japão e Itália) em qualquer ocasião e, no contexto escolar, os decretos de 1938 e 1941 proibiram o uso de qualquer outra língua na escola, que não fosse a portuguesa, e a produção e importação de livros didáticos em língua estrangeira (FREITAS; BALTHAZAR; LUNATI, 2015). Zanini (2006) assinala que o português foi imposto em um contexto em que os alunos não falavam português nem em casa e nem na escola e, para que se adaptassem às exigências do período de interdição, eram duplamente castigados: na escola, recebendo castigos (inclusive físicos), caso não se adaptassem ao ensino em português; e em casa, já que seus pais consideravam os castigos na escola como uma desonra. Como salienta Payer (2001, p. 242), nesse período: “[...] interditou-se a língua, em suas canções, em suas homenagens, em suas narrativas, em suas orações. É uma interdição que violenta o que há de mais íntimo ao sujeito - sua história, sua crença, sua esperança -, provocando assim a divisão, partição, a clivagem... o estar e o não estar no Brasil, o ser italiano e o não ser.”.

O espaço para o ensino de italiano standart começou a ser timidamente retomado em 1949, quando, terminada a guerra, foi assinado o Protocolo de Declaração de Amizade e Cooperação entre o Brasil e a Itália para desenvolver recíprocas relações jurídicas, econômicas, culturais, técnicas e sociais. Em 1958 as relações se fortaleceram um pouco mais e foi assinado um acordo cultural entre Brasil e Itália, com o objetivo de fortalecer as relações literárias, artísticas, científicas e técnicas, segundo o qual o Brasil comprometeu-se:

[...] a introduzir o estudo facultativo da língua italiana nos estabelecimentos oficiais de ensino médio e a reconhecer a sua validade nos programas de exame em posição de paridade com a língua estrangeira mais favorecida, entre aquelas para as quais é previsto o mesmo tipo de ensino, bem como a manter e desenvolver o estudo do italiano nas Universidades e Institutos Superiores. (ACORDO CULTURAL ENTRE O GOVÊRNO DA REPÚBLICA DOS ESTADOS UNIDOS DO BRASIL E O GOVÊRNO DA REPÚBLICA ITALIANA, 1958 apud FABRO, 2015, p. 115).

Apesar de algumas dessas ações nunca terem sido colocadas em prática - tal como a validade nos programas de exame em posição de paridade com a língua estrangeira mais favorecida -, a assinatura do acordo contribuiu para um movimento de revalorização da cultura italiana no Brasil que se fortaleceu a partir da década de 1970, segundo Freitas, Balthazar e Lunati (2015). As autoras ressaltam que as associações ítalo-brasileiras voltaram a ter importante papel no ensino de italiano, nesse período, firmando parcerias com vários municípios e trazendo grande investimento financeiro para o ensino de língua italiana no Brasil.

O movimento de expansão no ensino da língua ganhou ainda mais impulso com a Lei de Diretrizes e Bases da Educação Nacional de 1996 que estabeleceu, tanto no Ensino Fundamental quanto no Ensino Médio, a obrigatoriedade do ensino de pelo menos uma

Forum lingüístic., Florianópolis, v.15, n 4, p.3395-3411, out./dez. 2018. 
língua estrangeira moderna, ficando a escolha a cargo da comunidade escolar ${ }^{1}$ (BRASIL, 1996). Os Parâmetros Curriculares Nacionais para o $3^{\circ}$ e $4^{\circ}$ ciclos do Ensino Fundamental esclareciam que as instituições de ensino gozavam de liberdade na escolha da língua estrangeira a ser ensinada, devendo levar em consideração fatores históricos, fatores relativos às comunidades locais e fatores relativos à tradição (BRASIL, 1998). Tendo em conta tais fatores, muitas comunidades, que receberam entre os séculos XIX e XX grande fluxo de imigrantes provenientes da península itálica, optaram pelo ensino de língua italiana por conta das relações culturais, afetivas e de parentesco com a Itália. Para atender tal demanda, foram implementados projetos para a formação de professores de língua italiana, dentre os quais o Projeto Magister Letras UFSC, desenvolvido pela Secretaria do Estado e do Desporto de Santa Catarina - SED e implementado com a parceria da Universidade Federal de Santa Catarina entre os anos de 1997 e 2001, tendo formado 164 professores. O projeto enviou os professores da UFSC para cidades do interior do Estado de Santa Catarina (Jaraguá do Sul, Rodeio, Criciúma, Ibirama, Rodeio e Araranguá) com os objetivos de (i) complementar a formação em língua estrangeira de alunos já licenciados em Letras (oferecendo, nesse caso, somente habilitação em Espanhol); (ii) oferecer licenciatura plena em língua e literatura estrangeiras (alemão e italiano) a professores da rede sem formação superior (SILVA, 2003).

Infelizmente, o movimento expansionista não durou muito tempo. Ainda muito dependente dos recursos vindos da Itália, o ensino da língua italiana no Brasil começou novamente a modificar-se quando o governo italiano, sentindo os efeitos da crise financeira mundial de 2008, reduziu gradativamente os investimentos para o ensino da língua fora da península. O gráfico a seguir, sobre o número de alunos atendidos em Santa Catarina pelo convênio entre o Centro de Cultura Italiana Paraná-Santa Catarina e as prefeituras do Estado, retrata bem tal situação:

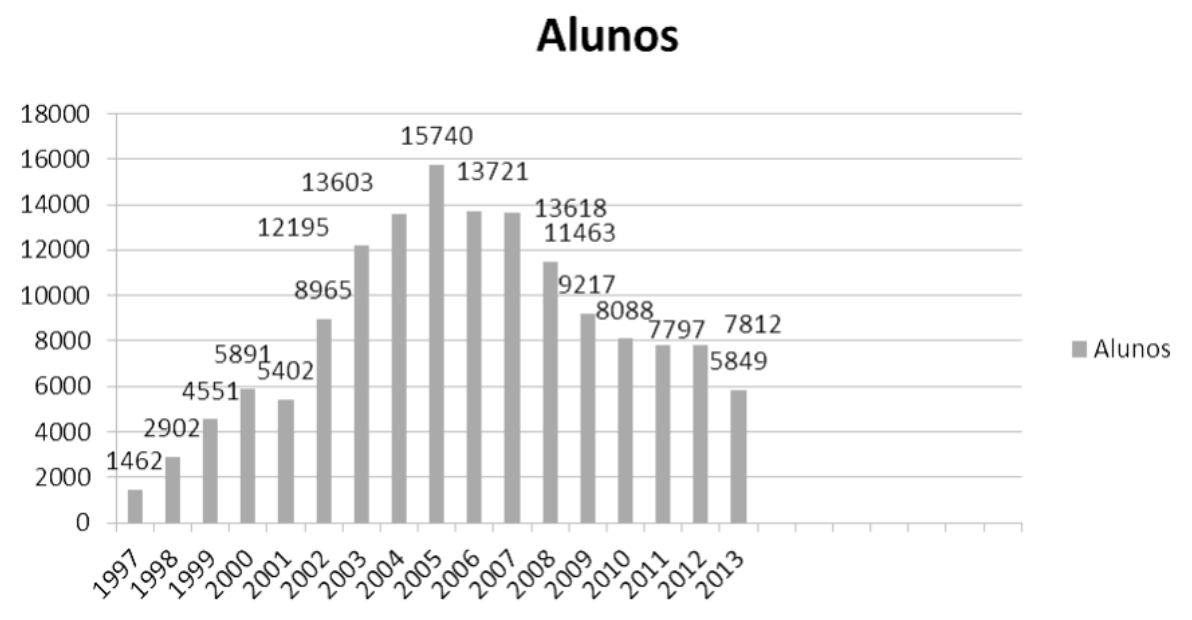

Gráfico : Número de alunos por ano nas escolas da Rede Municipal de Ensino de Santa Catarina.

Fonte: Fabro (2015)

A situação das línguas não hegemônicas, dentre elas, o italiano, ficou ainda mais delicada a partir das alterações na Lei de Diretrizes e Bases da Educação Nacional, efetivadas com a aprovação da Lei n 13.415 , de 2017, que privilegia o ensino da língua inglesa. Até então, apesar da pressão pelo ensino da língua inglesa por seu papel na economia mundial e na difusão de informações a nível global, as instituições escolares gozavam de relativa liberdade para escolher a(s) língua(s) estrangeira(s) que seriam incluídas no currículo escolar. Infelizmente, a lei de 2017 já não permite tal escolha, estabelecendo o ensino obrigatório de língua inglesa tanto no Ensino Fundamental (a partir do sexto ano) quanto no Ensino Médio, sendo que outras línguas estrangeiras podem ser ofertadas em caráter optativo no Ensino Médio, dando-se preferência ao espanhol (BRASIL, 1996).

\section{MAPEAMENTO DA OFERTA DO ENSINO DE LÍNGUA ITALIANA NAS ESCOLAS PÚBLICAS DE SANTA CATARINA}

\footnotetext{
${ }^{1}$ Além disso, a LDB de 1996 estabelecia que, além de uma língua estrangeira moderna, uma segunda língua poderia ser ofertada em caráter optativo no Ensino Médio, segundo as possibilidades da instituição (BRASIL, 1996).
} 
Diante do espaço reduzido para o ensino de língua italiana é urgente entender o cenário. Contudo, temos dados insuficientes e esparsos sobre o ensino do italiano no Brasil e em Santa Catarina. Ortale e Zorzan (2013) realizaram mapeamento dos municípios do Brasil onde há oferta de língua italiana em escolas públicas por meio de consulta às universidades brasileiras que oferecem cursos de graduação em língua italiana, aos consulados italianos e às associações ítalo-brasileiras.

Àquela época, em 2013, os autores salientavam as dificuldades para obter informações precisas, já que muitas das instituições locais consultadas não tinham dados muito claros a respeito do ensino de língua italiana em sua região. Ainda assim, segundo os pesquisadores, foi possível constatar que havia aproximadamente 90 municípios que ofereciam a língua na rede pública, mas que tal oferta já se encontrava em declínio. Outra informação relevante é que quase todas as iniciativas para o ensino da língua da península partiam da parceria entre prefeituras e associações culturais italianas, evidenciando o distanciamento das universidades públicas e dos estados brasileiros em relação às políticas educacionais voltadas à língua italiana.

Sobre a situação de Santa Catarina, os autores assinalam que, apesar de menos expressivo do que no Rio Grande do Sul, o movimento migratório de habitantes da península itálica para o estado de Santa Catarina foi intenso nos anos finais do século XIX:

Os trentinos se dirigiram para a região norte do estado, fundando a cidade de Nova Trento e "se espalhando pelas colônias da área conhecida como Pomeranos” (TRENTO, 1989, p.86). Já os lombardos e vênetos rumaram para o sul do estado povoando as colônias de Azambuja, Urussanga e Tubarão. Segundo o autor, duas colônias se destacam na história da imigração italiana no estado de Santa Catarina por se tornarem as únicas com predomínio da população italiana: Urussanga, que em 1878, contava com 7000 italianos e Nova Venezia, que em 1884, tinha uma população de 2885 italianos (ORTALE; ZORZAN, 2013, p. 126)

Dada a grande quantidade de descendentes dessa população que aportou no Estado e a demanda pelo ensino de língua italiana, o Centro de Cultura Italiana Paraná-Santa Catarina, contando com apoio logístico e financeiro do governo italiano, assinou acordos com algumas prefeituras, visando a garantir o ensino de língua e cultura italiana em escolas municipais localizadas em regiões onde a imigração foi mais significativa: i) no horário escolar - em Arroio Trinta, Laurentino, Morro Grande, Nova Veneza, Salto Veloso e Siderópolis; ii) no contraturno - em Balneário Camboriú, Concórdia, Jaborá, Jaraguá do Sul, Joinville, Mafra e Massaranduba. A maioria dos professores não tinha formação universitária, eram funcionários do próprio município e recebiam do Centro de Cultura Italiana (CCI) a formação para atuar em sala de aula, apoio pedagógico e material didático. Além do convênio CCIprefeituras, a Secretaria Estadual de Educação assumiu parte da responsabilidade pela oferta de italiano no currículo escolar por meio da contratação de 10 professores efetivos com formação em língua italiana que passaram a lecionar em seis municípios: Arroio Trinta, Ascurra, Iomere, Lindóia do Sul, Nova Trento e Rodeio (ORTALE; ZORZAN, 2013). Freitas, Balthazar e Lunati (2015), acrescentam que, em 2009, esses 10 professores atendiam 1489 alunos e que, em 2012, o número de professores chegou a 13 e 10 escolas passaram a ser atendidas.

Ortale e Zorzan (2013) concluem seu mapeamento, ressaltando sua incompletude e fazendo o convite para que mais pesquisadores engajem-se na tarefa de mapear o ensino de italiano como ponto de partida para repensar a formação docente e a participação da universidade em todo esse processo.

Convite aceito, procuramos por dados mais recentes que pudessem ser comparados aos que já estavam disponíveis, entrando em contato com a Secretaria de Estado da Educação de Santa Catarina (SED), com as Gerências Regionais do Estado em Timbó e Brusque, com o Centro de Cultura Italiana Paraná-Santa Catarina (sediado em Curitiba) e com o Colégio de Aplicação da Universidade Federal de Santa Catarina.

A Gerência de Avaliação da Educação Básica e Estatísticas Educacionais, órgão da Secretaria de Estado da Educação de Santa Catarina, forneceu dados atuais sobre o ensino de língua italiana na rede estadual, os quais apresentamos na tabela a seguir ${ }^{2}$ :

\footnotetext{
${ }^{2}$ A tabela com maior detalhamento, fornecida pelo órgão da Secretaria, encontra-se no anexo 1.
} 


\begin{tabular}{c|c|c} 
Município & Nome do curso & $\begin{array}{c}\text { Alunos } \\
\text { matriculados }\end{array}$ \\
\hline Lindóia do Sul & Fundamental - anos finais & 28 \\
\hline Arroio Trinta & Fundamental - anos finais & 61 \\
\hline Arroio Trinta & Médio & 10 \\
\hline Arroio Trinta & Médio inovador & 37 \\
\hline Iomerê & Médio & 24 \\
\hline TOTAL & & 160
\end{tabular}

Tabela 1: Oferta de ensino de língua italiana na rede pública estadual de SC

Fonte: Gerência de Avaliação da Educação Básica e Estatísticas Educacionais - SED-SC (2017)

Comparando-se as informações com os dados de Ortale e Zorzan (2013), constata-se que o italiano é ofertado em apenas metade dos colégios que antes ofereciam a língua: Arroio Trintra, Lindóia do Sul e Iomerê. A redução fica mais evidente quando se contrasta o número de professores efetivos, que de $10 \mathrm{em}$ 2013, passou para $3 \mathrm{em} 2017$, atendendo a apenas 160 alunos que constam como matriculados. Em conversa telefônica com funcionárias das Gerências Regionais de Brusque e Timbó, foram levantadas algumas das possíveis causas para tal diminuição de oferta: a falta de professores (já que muitos se aposentaram e não ocorreram novas contratações) e a falta de demanda pela língua (já que poucos alunos se inscreviam na disciplina, preferindo o inglês).

O segundo passo para tentar entender a situação do ensino de italiano em âmbito público foi buscar informações junto ao Centro de Cultura Italiana Paraná-Santa Catarina (sediado em Curitiba). Apesar do número de municípios atendidos ter decaído nos últimos anos, a partir de informações repassadas por e-mail, confirmou-se que o convênio do CCI com as prefeituras do estado garante a oferta de língua italiana para 17 municípios: Arroio Trinta, Concórdia, Cocal do Sul, Jaraguá do Sul, Joinville, Lacerdópolis, Laurentino, Macieira, Mafra, Massaranduba, Morro Grande, Nova Veneza, Rodeio, Salto Veloso, Siderópolis, Treviso e Urussanga. Maior detalhamento sobre esta situação é fornecido a seguir:

\begin{tabular}{|c|c|c|c|c|c|c|c|c|c|c|c|}
\hline dif Centro di & \multicolumn{4}{|c|}{ CURRICOLARI } & \multicolumn{3}{|c|}{ EXTRACURRICOLARE } & \multirow[b]{2}{*}{$\begin{array}{l}\text { di cui Tot. } \\
\text { Corsi A }\end{array}$} & \multirow[b]{2}{*}{$\begin{array}{l}\text { di cui Tot. } \\
\text { Corsi B }\end{array}$} & \multirow[b]{2}{*}{$\begin{array}{l}\text { Tot. corsi } \\
\text { Formazione }\end{array}$} & \multirow[b]{2}{*}{$\begin{array}{l}\text { TOTALE } \\
\text { dell'Ente }\end{array}$} \\
\hline Aseraliana & INFANZIA & PRIMARIA & SECONDARIA & Totale & PFIMARIA & SECONDARIA & Totale & & & & \\
\hline CORSI & 25 & 173 & 69 & 267 & 3 & 12 & 15 & 8 & 274 & 3 & 285 \\
\hline ALUNNI & 404 & 3.103 & 1.289 & 4.796 & 74 & 142 & 216 & 102 & 4.910 & 11 & 5.023 \\
\hline DOCENTI (2) & 3 & 14 & 9 & 26 & 2 & 3 & 5 & 1 & 20 & 3 & 34 \\
\hline
\end{tabular}

Figura 1: números sobre o convênio CCI e prefeituras de Santa Catarina

Fonte: Centro de Cultura Italiana Paraná-Santa Catarina (2017)

Segundo os dados, a oferta através do convênio é muito maior do que a garantida pela rede estadual de ensino. São atendidos 5.023 alunos em todo o ensino básico, a maior parte deles (4.796) no horário escolar, contando com a participação de 34 professores nesse processo. A partir da figura, não é possível entender como se dá essa distribuição por município, mas percebe-se que a maior parte da oferta se concentra no Ensino Fundamental.

No Colégio de Aplicação da UFSC, importante espaço para a realização dos estágios supervisionados dos alunos dos cursos de licenciaturas da universidade, assim como em toda a região da grande Florianópolis, não há professor de língua italiana contratado. Segundo a professora Maristela Campos, Coordenadora de Línguas Estrangeiras do Colégio de Aplicação (contatada via e-mail), a língua italiana já foi ofertada aos estudantes dos anos iniciais, através de projeto envolvendo estudantes em estágio supervisionado 
do Curso de Licenciatura em Letras-Italiano, mas a oferta foi interrompida. A Coordenadora não soube relatar os motivos que levaram à extinção da oferta, mas mostrou-se aberta para novas iniciativas, afirmando ser possível implementar novamente o ensino da língua através de projeto de extensão, principalmente nos anos iniciais. Nas demais séries, a língua poderia ser ofertada no contraturno, sendo necessária uma consulta à comunidade escolar para saber do interesse/demanda.

Diante do levantamento realizado, seria relevante entender os motivos (além dos financeiros e dos relacionados às alterações na LDB) para a diminuição tão acentuada da oferta e da procura pelo idioma. Em trabalho recente, Baraldi, Hass e Ortale (2016) evidenciam a diminuição da oferta de língua italiana nos Centros de Estudos de Línguas (CEL) do Estado de São Paulo, projeto pioneiro que visa a oferta de várias línguas para alunos da rede pública estadual. Segundo as autoras, o ensino de italiano está presente em 15\% dos CEL, mas essa oferta já foi maior e poderia/deveria ser ampliada, já que o Estado de São Paulo foi o que recebeu o maior número de imigrantes vindos da península. Dentre os fatores para a queda da oferta foram listados: o reduzido número de alunos por sala, a falta de professores, a pouca divulgação, a falta de incentivo dos pais e a falta de interesse dos alunos. Sobre a falta de professores, as autoras argumentam que é urgente que o grande fosso que há entre os cursos de graduação em Letras-Italiano e as escolas municipais e estaduais seja superado através de projetos de extensão que atendam a comunidade escolar.

Um dos fatores que nos chama a atenção, dentre aqueles listados, é a falta de interesse dos alunos, o que também nos foi relatado pela Gerência Regional de Brusque-SC. Será que de fato há um distanciamento dos estudantes em relação ao ensino de italiano? Se isso ocorre, qual seria a motivação? Estaria ela relacionada às condições em que se dá o ensino-aprendizagem? Estaria relacionada ao método adotado pelos professores? Ou será que os alunos, mesmo em comunidades que receberam grande volume de imigrantes, já não se sentem mais identificados com a língua e a cultura de origem? E se esta última hipótese fosse verdadeira, o que estaria por trás da falta de identificação? Seria a distância entre o italiano standart e os dialetos que circulam nas comunidades? Seria a identificação com outros grupos ou comunidades para além das fronteiras locais? Seria a falta de informação sobre as possibilidades que se abrem com o aprendizado da língua?

Enfim, realmente são muitas as questões que emergem e que permanecem sem resposta e, na próxima seção, tentamos apontar possíveis caminhos para entender e lidar com a situação através do olhar das teorias linguísticas para as demandas contemporâneas e também das novas abordagens para o ensino de línguas estrangeiras.

\section{REFLEXÕES SOBRE O ENSINO DE LÍNGUA ITALIANA A PARTIR DAS DEMANDAS CONTEMPORÂNEAS: NOVAS AGENDAS PARA AS TEORIAS LINGUÍSTICAS E PARA O ENSINO DE LE}

Os processos de ensino/aprendizagem de línguas, maternas ou estrangeiras, envolvem aspectos que não podem ser contemplados por nenhuma teoria linguística por si só, sendo assim necessária uma abordagem transdisciplinar, na qual o foco recai sobre o problema enfrentado, partindo-se das demandas sociais. Esse olhar é coerente com as teorias pós-modernas críticas (PENNYCOOK, 2006), pós-coloniais (MAKONI; MEINHOF, 2006) e pós-método (KUMARAVADIVELU, 2003), por exemplo, as quais centralizam o aspecto ideológico da linguagem.

Em contraste com as pressuposições tradicionais em estudos da linguagem - segundo as quais as ideologias são apartadas da matéria de estudo e as identidades são vistas como estáticas, unitárias e dadas -, entendemos que a construção das identidades se dá de forma contínua, múltipla, conflitante e negociada com e pela linguagem, associando-se a muitos outros sistemas simbólicos. Em uma perspectiva integracionista, recusam-se as dicotomias linguístico e não linguístico, conteúdo e língua, língua e ação, aprendizagem e vida. (MAKONI, 2011), por uma visão mais holística de língua e do papel dos sujeitos nas práticas históricas, culturais e sociais nas quais se inserem. A partir desse olhar sobre a linguagem, questões centrais podem ser lançadas sobre o ensino de língua italiana e das línguas estrangeiras em geral: por que ensinar uma determinada LE? Qual língua ensinar? Qual o papel do professor de LE? Qual a relação dos sujeitos com as línguas e as culturas com as quais entram em contato?

Partindo de um olhar crítico e situado para as práticas linguísticas - o qual considera as línguas como invenções políticas pautadas em relações de poder contextualizadas e que envolvem também interesses econômicos (MAKONI; MEINHOF; 2006; 
PENNYCOOK, 2006; RAJAGOPALAN, 2013; SEVERO; MAKONI, 2015) -, entende-se que as ações voltadas à preservação e ao resgate de línguas em contexto de imigração, assim como o ensino em contextos plurilíngues, devem estar pautadas nos interesses dos sujeitos e das comunidades em questão e em sua relação com as línguas que usam, sua cultura e seu contexto histórico.

Nesse contexto, mencionamos que a Assembleia Legislativa de Santa Catarina, através da Lei n ${ }^{\circ}$ 14.951, de 11 de novembro de 2009, decretou o Talian (dialeto italiano de origem veneta) como patrimônio histórico e cultural do estado, sendo que no município de Nova Erechim (atendendo a pedido de lideranças comunitárias) o dialeto/língua já foi cooficializado na forma da Lei Municipal $n^{\circ}$ 1783 de 11/08/2015. Além dessa, há algumas outras iniciativas para a cooficialização no estado, por exemplo, no município de Nova Veneza, mas tais movimentos ainda não produziram ações efetivas, já que em Nova Erechim, nem o Italiano e nem o Talian são ofertados nas instituições de ensino do município (MORELLO, 2015).

Nesse sentido, compartilhamos com Azevedo (2015) a ideia de que a cooficialização de línguas de origem em contextos de imigração não garante a permanência e o ensino dessas línguas nas comunidades. A autora compara as políticas linguísticas implementadas em relação às línguas trazidas por imigrantes germânicos em Antônio Carlos-SC e em Santa Maria do Herval-RS, evidenciando que a cooficialização não garante a permanência das línguas.

Em Antônio Carlos, optou-se por cooficializar o Hunsrückisch, mas não houve nenhum tipo de política para garantir a viabilização do ensino e o uso da língua entre os jovens e as futuras gerações ${ }^{3}$. Já em Santa Maria do Herval, decidiu-se não cooficializar o Hunsrik, o que traria gastos para o município por conta da exigência legal de, a partir da cooficialização, disponibilizar em todas as esferas administrativas do município pessoas que falam a língua cooficializada. Ao invés disso, o município optou em investir no projeto Hunsrik/Plat Taytx que visa a promover o ensino de Hunsrik nas escolas municipais.

Entendemos que as línguas vivem na medida em que há o interesse dos sujeitos em usá-las em suas práticas cotidianas e as políticas públicas relacionadas às línguas nesses contextos deveriam estar pautadas nesses interesses, principalmente nos interesses dos jovens/adolescentes que seriam os responsáveis por garantir a permanência das línguas nas comunidades na atual e futura geração. Sendo assim, faz-se necessário perguntar: os adolescentes em contextos de imigração italiana querem aprender italiano (ou seu dialeto de origem)? Quais seriam as razões para sua aproximação ou distanciamento da língua? Estas são questões relevantes para a implementação de políticas linguísticas que levam em consideração os sujeitos e suas demandas atuais.

Tais questionamentos apontam para a importância de também se discutir sobre qual língua de fato vive em contextos de imigração e qual a relação daquela língua com a língua estrangeira moderna que supostamente corresponderia a certa comunidade. Makoni e Meinhof (2006), interessados no contexto africano pós-colonial, desconstroem o conceito de língua tal como tomado por governos e linguistas, mostrando que tal conceito muitas vezes não se relaciona com as efetivas práticas linguísticas dos sujeitos. Por exemplo, muitas das práticas de oralidade encaradas por teóricos como representações do multilinguismo africano não são reconhecidas por seus falantes como línguas diferentes. Tendo em vista tal problemática, é necessário construir teorias locais que, partindo da prática, possam ir ao encontro da vida das pessoas em suas comunidades, ou seja, a teoria deveria ser moldada a partir da prática social.

É nesse sentido que entendemos ser necessário pensar o ensino de língua italiana nas comunidades em contexto de imigração. Para começar, é importante considerar o contexto histórico e social que promoveu a chegada dos imigrantes nas comunidades nas quais se instalaram em Santa Catarina e qual, ou quais, eram as línguas que traziam.

Apesar do processo de unificação da Itália ter culminado em 1861, o uso dos diversos dialetos ${ }^{4}$ - imperou até meados do século XX quando, no período pós-guerra, as políticas educacionais italianas estabeleceram restrições mais rígidas à presença dos dialetos em salas de aula, vistos como obstáculos ao aprendizado do italiano standart (FREITAS; BALTHAZAR; LUNATI., 2015). Sendo assim,

\footnotetext{
${ }^{3}$ A cooficialização em Antônio Carlos partiu da iniciativa do vereador Altamiro Kretzer, sem levar em conta uma análise cuidadosa da realidade linguística do município.

${ }^{4}$ A questão dos dialetos na Itália é bastante particular. Não se trata de variedades de uma mesma língua, mas podemos dizer que há várias línguas que podem ser bastantes distintas em termos fonológicos, morfológicos, sintáticos e lexicais, impossibilitando, até mesmo, a comunicação entre falantes de dialetos/línguas distintos/as.
} 
é bastante evidente que o que os imigrantes da península trouxeram ao Brasil nos períodos de maior fluxo migratório, entre a segunda metade do século XIX e a primeira metade do século XX, não foi uma língua, mas várias línguas.

Em Nova Trento, por exemplo, município catarinense que recebeu grande fluxo migratório da península itálica no final do século XIX e início do século XX, as cerca de 11 mil pessoas que se estabeleceram na colônia, a partir de 1875, vinham de regiões distintas do norte da Itália, da Valsugana, no Alto Vale do Brenta, no Trentino e de Monza. Esses imigrantes trouxeram consigo línguas distintas e defrontaram-se com as outras línguas já existentes no contexto brasileiro: no convívio com os falantes de português, com os falantes de origem germânica que chegaram no mesmo período e com os povos indígenas que já habitavam a região (NOVA TRENTO, 2014).

Freitas, Balthazar e Lunati (2015) assinalam que, embora o governo italiano tenha tomado medidas para ensinar o italiano padrão aos cidadãos fora da pátria, o acesso ao italiano standart no Brasil era limitado pela falta de professores que usassem a língua, pelas precárias condições das escolas e pela falta de identificação dos italianos com a instituição "escola". Em contrapartida, os dialetos de origem floresciam nos contextos sociocomunicativos cotidianos e passaram a ser usados até mesmo nas celebrações litúrgicas, além do latim. Os problemas se intensificaram a partir da década de 1930, quando a política nacionalista brasileira passou a exigir que a língua portuguesa ocupasse os espaços oficiais e em 1942 proibiu-se o uso das línguas que circulavam ou se relacionavam com os países inimigos, como já apontamos na seção 2 .

Segundo as autoras, a postura de vergonha em relação à língua de origem só mudou em meados da década de 1970, quando se deu início ao movimento de revalorização da cultura italiana e o governo italiano passou a investir no ensino da língua para os descendentes de imigrantes. Contudo, as pesquisadoras alertam que os manuais e demais materiais didáticos produzidos na Itália, em italiano standart, desconsideravam os dialetos e as tradições locais, afastando os descendentes do aprendizado e da identificação com a língua italiana. As autoras concluem seu texto, sugerindo que no ensino da língua italiana sejam levados em conta os aspectos sociolinguísticos locais e a realidade dialetal da região como ponte de acesso para a aquisição do italiano standart e que a formação do professor o prepare para lidar com a diversidade linguística.

Levando em conta o quadro acimo exposto, resta-nos saber que conhecimentos sociolinguísticos seriam esses. De qual sociolinguística, afinal, estamos falando e qual seria sua agenda? Podemos adiantar que entendemos relevante o olhar de uma abordagem sociolinguística renovada e conectada com as demandas contemporâneas.

Se na sociologia da modernidade a sociedade era vista como totalidade unificada e integrada da qual o sujeito fazia parte e a partir da qual conduzia suas ações, na pós-modernidade há a compreensão de que nossos agrupamentos sociais são baseados em opções mutáveis e que temos um papel maior nessas configurações, decidindo o que é melhor para nós mesmos (BAUMAN, 2003). Nessa mesma direção, Hall (2005) também aposta na condição dos sujeitos como agentes na configuração de sua própria realidade, capazes de fazer escolhas diante de uma série estilos e produtos culturais aos quais são expostos. O autor argumenta que temos vivido mudanças sociais intensas desde o final do século XX, o que gera uma fragmentação das "[...] paisagens culturais de classe, gênero, sexualidade, etnia, raça e nacionalidade, que, no passado, nos tinham fornecido sólidas localizações como indivíduos sociais [...]" (HALL, 2005, p. 9), provocando uma espécie de crise de identidade com implicações tanto para a constituição de uma identidade individual, quanto para a relação entre o indivíduo e o mundo social.

As identidades, antes entendidas como estáveis, mostram-se múltiplas e os processos de identificação (que levam em conta a relação dos indivíduos, comunidades e culturas) apresentam-se em mudança contínua, provisórios e variáveis nas palavras do autor. O que a modernidade tardia nos apresenta é:

[...] o sujeito pós-moderno conceptualizado como não tendo uma identidade fixa, essencial ou permanente. A identidade torna-se uma "celebração móvel": formada e transformada continuamente em relação às formas pelas quais somos representados ou interpelados nos sistemas culturais que nos rodeiam (Hall, 1987). [...] Dentro de nós há identidades contraditórias, empurrando em diferentes direções, de tal modo que nossas identificações estão sendo continuamente deslocadas. [...] na medida em que os sistemas de significação e 
representação cultural se multiplicam, somos confrontados por uma multiplicidade desconcertante e cambiante de identidades possíveis, com cada uma das quais poderíamos nos identificar - ao menos temporariamente" (HALL, 2005, p. 12-13).

Para Hall (2005), a globalização e os fluxos culturais em um mundo de fronteiras dissolvidas têm três possíveis resultados: i) a homogeneização das culturas locais, devido à difusão da cultura de massa; ii) o reforço das identidades locais como sinal de resistência à globalização ${ }^{5}$; iii) a hibridização das identidades locais, a partir das influências externas, dando origem a novas identidades. Considerando tais resultados é pertinente nos questionarmos sobre como as comunidades em contextos de imigração italiana em Santa Catarina, principalmente os jovens - os quais estão mais expostos e conectados com o fluxo informacional e com as tecnologias da comunicação -, posicionam-se diante da dissolução das fronteiras físicas e virtuais. Estariam eles submetidos a uma cultura de massa, reforçando suas identidades locais, ou construindo identidades híbridas a partir dos mais variados contatos?

As mudanças sociais características da pós-modernidade, afetam o fazer científico e percebe-se nas últimas três décadas uma acentuada mudança nos interesses da sociolinguística que se aproxima cada vez mais de uma antropologia linguística, apostando que aspectos culturais podem ter muito a dizer para as investigações linguísticas (GUMPERZ; COOK-GUMPERZ, 2008). A partir do entendimento de que identidades são mutáveis e plurais e "[...] a língua está sujeita a variações e mudanças, justamente porque linguagem e identidade estão mutuamente implicadas [...]" (SEVERO, 2007, p. 14), a sociolinguística precisa levar em conta que as categorias sociais são construções históricas, políticas e localmente motivadas, através das quais os indivíduos constituem suas identidades.

Se na década de 1960 a sociedade moderna com a qual lida Labov em seus estudos fundantes da área era hierarquicamente mais estruturada, através de divisões claras de classe social, região, gênero, raça, etc., a sociedade da modernidade tardia (ou pósmodernidade) caracteriza-se por sua complexidade, fragmentação, contradição e grande mobilidade geográfica, social e virtual, o que requer teoria e métodos de pesquisa renovados. Não basta mais acionarmos a variação nos planos diatópico, diamésico, diastrático e diafásico, buscando enquadrar os sujeitos ou classificá-los. Ao invés disso, é mais produtivo tentar entender como os sujeitos se percebem em relação às diversas comunidades com as quais se relacionam e como tal percepção contribui para a constituição das suas múltiplas identidades. Dentro de certos limites, já que as pressões sociais estão sempre em jogo, os sujeitos podem fazer escolhas sobre seu consumo e assumir certos atributos sociais de diferentes classes e, nesse sentido, a noção de estilo que pode abarcar vários recursos simbólicos, incluindo a linguagem - torna-se o centro dos estudos sociolinguísticos na pósmodernidade (COUPLAND, 2007).

Nos estudos sociolinguísticos iniciais de Labov e nas pesquisas que seguiram a mesma abordagem, chamada por Eckert (2012) de The survey era ${ }^{6}$, o foco estava no estabelecimento e descrição de padrões de uso de comunidades urbanas em termos quantitativos, considerando categorias sociodemográficas amplas, como sexo, idade e classe social. Nessa fase, entendia-se que a diversidade estilística poderia ser disposta em um eixo de grau de atenção à fala e o significado social era considerado apenas em termos de prestígio e estigma.

Em outros estudos com uma abordagem etnográfica, o olhar é deslocado para o significado social dos usos linguísticos em comunidades menores, isto é, os conflitos sociais nas comunidades são tomados como motivadores do uso de formas linguísticas que refletem o modo de identificação dos falantes com suas comunidades. Emerge nessa abordagem o conceito de comunidade de prática, um agregado de pessoas que, reunidos com objetivos comuns ou em torno de um empreendimento comum, passam a compartilhar as formas de fazer as coisas, de falar, suas crenças e valores (RICKFORD, 1986; ECKERT, 1989).

\footnotetext{
${ }^{5}$ Para Hall (2005), situações extremas de racismo cultural, em que grupos étnicos dominantes sentem-se ameaçados com a entrada de novos grupos, são exemplos dos contextos em que pode emergir o fortalecimento de identidades locais ou a re-identificação com as culturas de origem.

${ }^{6}$ Eckert (2012), evitando compartimentalizações, apresenta três tendências distintas para os estudos da variação que denomina de ondas e que não devem ser entendidas como momentos sucessivos, mas como fases que podem conviver e sobrepor-se: the survey era, a abordagem etnográfica e a perspectiva estilística.
} 
Atualmente, na chamada perspectiva estilística, ganha força "[...] uma visão da variação como reflexo das identidades e categorias sociais para a prática linguística em que falantes se colocam na paisagem social através da prática estilística. ”" (ECKERT, 2012, p. 94). Nessa perspectiva os falantes recebem o papel de protagonistas na construção de seus discursos e na escolha das formas linguísticas, ganhando relevo: i) os modos de caracterização particulares que contribuem para a construção da persona, ou seja, o olhar sobre o indivíduo como agente e construtor de seus vários estilos e identidades acionados a depender da situação comunicativa e de seu papel social nela; ii) a preocupação com a busca dos significados sociais que motivam os usos particulares (SOUKUP, 2011).

Nessa abordagem mais recente, estilo na linguagem é assumido como uma das partes de um conjunto maior que envolve outros sistemas simbólicos, como a gestualidade, os diversos modos de se vestir ou de comportar-se, etc. Nesse sentido, é crucial a noção de distintividade, ou seja, o modo pelo qual os falantes, como agentes no espaço social (e sociolinguístico), negociam suas posições e objetivos dentro de um sistema de distinções e possibilidades (IRVINE, 2001).

Essa nova agenda da sociolinguística nos oferece abertura para lançar questões relevantes relacionadas ao uso e ao ensino da língua italiana em Santa Catarina: como os descendentes de imigrantes italianos relacionam-se com a cultura e com a língua trazidas pelos seus antepassados? Sua identificação ou afastamento se refletem em suas escolhas linguísticas? Há ainda traços que marcam uma certa origem italiana na fala dos jovens que vivem em comunidades em contexto de imigração? Quais os reflexos que isso teria para o ensino de língua italiana?

A título de exemplo, o sentimento de italianidade parece estar presente no discurso dos moradores do município de Nova Trento$\mathrm{SC}^{8}$ e nos últimos anos têm sido cada vez mais comuns manifestações de orgulho da identidade local e das tradições de herança. Contudo - transpondo para a realidade de Nova Trento as observações feitas por Leal (2007) em relação ao resgate da identidade florianopolitana -, questiona-se se seria esse um sentimento que emerge da própria comunidade ou se se trata de atitude muito mais política e institucionalizada, ligada a organizações de difusão cultural e à mídia e que se relaciona diretamente com os novos interesses turísticos da cidade de Madre Paulina.

Tal questionamento parece fazer ainda mais sentido diante do estranho fato de que, em contraste com o suposto movimento de resgate cultural, o ensino de língua italiana, que antes era garantido pelo estado no Colégio Francisco Mazzola, deixou de ser ofertado ${ }^{9}$. O que está por trás da ausência da oferta? Os jovens descendentes de imigrantes já não se identificam com a língua de seus antepassados? Os jovens não conseguem estabelecer uma ponte entre dialetos e o italiano standart que é ensinado? Ou os jovens identificam-se com uma cultura de massa e com outros grupos para além das fronteiras da cidade?

Ainda sobre a nova agenda de estudos da sociolinguística, Rampton (2006) ressalta que as mudanças de interesse da sociolinguística fazem parte de um movimento mais geral das ciências sociais - que deixam de tentar identificar os traços centrais de grupos ou instituições e passam a colocar foco no fluxo de pessoas, no conhecimento, nos textos, etc. - e questiona que implicações as mudanças relacionadas à sociologia e à sociolinguística têm para um novo papel da Linguística Aplicada (LA) no campo de ensino de línguas estrangeiras:

O que acontece [...] quando as humanidades e as ciências sociais passam a focalizar novos tópicos e há um crescimento de interesse em fluxos culturais, em fronteiras e margens em vez de centros, e em incertezas e ambivalências? [...] O que acontece se $\mathrm{o}$ antiessencialismo penetra as discussões, e começamos a nos perguntar se os sentimentos de pertencimento a grupos não são socialmente construídos no aqui e no agora? (RAMPTON, 2006, p. 120).

\footnotetext{
7 "[...] a view of variation as a reflection of social identities and categories to the linguistic practice in which speakers place themselves in the social landscape through stylistic practice."

${ }^{8}$ Em setembro de 2017, em visita à cidade, coletamos opiniões informais de moradores do município a respeito do tema.

${ }^{9}$ Em contato telefônico com a Gerência Regional de Brusque-SC, foi possível descobrir que o Colégio não conta mais com o ensino de italiano desde 2012, mas os motivos não ficaram claros, parecendo estar relacionados à aposentadoria do(a) docente e ao fraco interesse pela língua.
} 
O autor considera que a LA e as pesquisas sobre o ensino de línguas estrangeiras precisaram redirecionar o foco, colocando aspectos históricos, culturais, identitários e ideológicos ainda mais no centro das discussões. É nessa direção que se orientam os estudos interculturais, visando uma postura reflexiva do aluno de línguas estrangeiras, na medida em que avaliam suas crenças pessoais e valorizam a pluralidade linguística e cultural que o cerca e o modo como o aprendizado da LE pode influenciar suas perspectivas de mundo e ressignificar suas ações no contexto onde vive. É nesse sentido que Landulfo (2016) defende que o ensino de línguas estrangeiras, muito mais do que um conjunto de técnicas e a aplicação de um material didático, envolve complexos mecanismos: cognitivos, afetivos, sociais, culturais e, principalmente, políticos e ideológicos.

Nessa perspectiva, a indissociabilidade entre língua e cultura é levada às últimas consequências na medida em que se entende que “[... essa língua não é uma abstração teórica e que não possui existência fora do contexto social de uso pelos seus falantes" (MENDES, 2008, p. 72). Além disso, também se entende que os materiais didáticos em língua estrangeira levem em consideração os aspectos culturais. A título de exemplificação, Landulfo (2016) menciona os materiais voltados ao ensino de língua italiana que não fazem a menor menção ao italiano suíço e nem ao menos às variações linguísticas em diversos níveis presentes no idioma. Segundo a autora, a meta para o ensino de línguas estrangeiras não deveria ser a fala do falante nativo, mas a transformação dos alunos em falantes interculturais.

Nesse sentido, o objetivo central do ensino de língua italiana não deveria ser o de levar o estudante a alcançar a mais pura essência do italiano standart, mas fornecer elementos para a apropriação intercultural dessa língua moderna que, sem desconsiderar as particularidades locais, lhe permita fazer deslizamentos contínuos e estabelecer as pontes necessárias entre sua herança dialetal, a língua oficial da península itálica e o português brasileiro.

Já percebemos nesse ponto que os interesses atuais das novas abordagens da sociolinguística, voltados à construção de identidades e para as práticas estilísticas, e da abordagem intercultural, direcionados para a simbiose língua-cultura, têm fortes pontos de articulação, já que, conforme Kurumavadivelu (2008), sendo a língua um dos mais poderosos símbolos de identidade, o modo como os sujeitos vinculam-se às línguas pode garantir ou impedir o aprendizado.

As considerações feitas nesta seção não visam responder sobre as demandas específicas da comunidade de Nova Trento-SC ou das demais comunidades de imigração italiana em relação ao ensino da língua italiana. Tal tarefa demandaria extensa pesquisa de campo, visando entender aspectos identitários locais e a relação entre sujeitos e língua diante da globalização e das demandas sociais contemporâneas. O que pretendemos com nossa problematização foi salientar a complexidade dos aspectos envolvidos para compreendermos os processos de identificação dos sujeitos com suas línguas de origem e apontar possíveis fatores que podem estar relacionados à diminuição do ensino de italiano nas escolas públicas de Santa Catarina.

\section{CONSIDERAÇÕES FINAIS}

Diante do quadro da oferta do ensino de italiano em Santa Catarina e tendo por base (i) uma perspectiva integracionista sobre a linguagem, (ii) um olhar crítico sobre as políticas linguísticas em contextos de imigração e (iii) uma abordagem sociolinguística preocupada com as demandas contemporâneas e alinhada com as agendas atuais para o ensino de línguas estrangeiras, acreditamos que, para pensar no ensino da língua e em políticas linguísticas para a ampliação da oferta na rede pública, seja necessário uma visão abrangente de aspectos históricos, sociais e individuais envolvidos na questão.

Por um lado, a partir de um olhar mais macro, é relevante ampliar nosso conhecimento sobre a situação do ensino de língua italiana, contando com o auxílio de dados quantitativos para a construção de um panorama mais geral. Buscamos contribuir nesse sentido através de um mapeamento atualizado da oferta da língua italiana na rede pública (municipal e estadual) no estado de Santa Catarina. Contudo, apontamos a necessidade de mapeamento mais aprofundado sobre a oferta do ensino nas escolas da rede estadual e municipal e nas comunidades em contexto de imigração, buscando mais detalhes sobre as lacunas existentes no estado de Santa Catarina e sobre: o funcionamento de parcerias e convênios para o ensino da língua no Estado; os projetos já executados, em andamento e futuros; os municípios e unidades de ensino que são atendidos, o número de alunos atendidos e sua distribuição 
nos anos de ensino; o número de professores, seu vínculo contratual e sua formação; os espaços onde as aulas são ministradas; os métodos utilizados e os materiais didáticos disponíveis para o ensino, dentre outras informações.

Por outro lado, também julgamos necessário um olhar mais micro, buscando obter informações aprofundadas sobre a relação sujeitos-língua/cultura e seu reflexo para o ensino de língua italiana. Acreditamos que a realização de pesquisas de base etnográfica e estilística em comunidades de prática de jovens em contexto de imigração italiana possam nos fornecer informações qualitativas e específicas sobre (i) seus movimentos de aproximação e distanciamento em relação à sua língua/cultura de herança e em relação à língua/cultura italiana; e sobre (ii) a presença ou ausência em sua fala de traços linguísticos relacionados a uma certa "italianidade".

Através desse olhar em profundidade, seria possível encontrar respostas a questões que a pesquisa mais ampla não nos permite investigar: Esses adolescentes são expostos à língua em contexto familiar? O que eles pensam sobre a língua falada pelos pais e avós? Fazem uso dessa língua? Em quais contextos? Há presença de marcas linguísticas que possam remeter a uma certa identidade italiana em sua fala?

De fato, apresentamos mais questões do que respostas, mas acreditamos que a tentativa de responder a essas perguntas em pesquisas empíricas futuras pode ser bastante relevante para planejar ações que visem garantir a oferta da língua em municípios catarinenses, caso essa seja uma demanda local. Além de implementar pesquisas mais detalhadas sobre a realidade do ensino de italiano na rede pública de Santa Catarina, também consideramos que, para lidar com a diminuição da oferta do ensino no estado e com as limitações impostas pela Lei no 13.415, de 2017, a ampliação do diálogo interinstitucional é urgente. Desse modo, tendo em mão informações sobre a realidade catarinense, é fundamental que Centros de Cultura, prefeituras, estado e universidade, possam interagir e construir ações conjuntas e efetivas, através de projetos de extensão, oficinas e parcerias, para garantir a oferta da língua nos municípios nos quais esse é um desejo da população e da comunidade escolar.

\section{REFERÊNCIAS}

AZEVEDO, L. K. A. de. Entre Babel e Babilônia: formas de discursivização e políticas linguísticas. Revista Working Papers em Linguística, Florianópolis, v. 16, n. 2, 2015, p. 162-184, 2015.

BARALDI, L. D.; HASS, J.; ORTALE, F. Do projeto “Italianando a San Paolo" ao mapeamento do Curso de Italiano nos Centros de Estudos de Línguas (CEL) do Estado de São Paulo: problemas, desdobramentos e propostas de ação. Revista de Italianística XXXII, São Paulo, p. 17-36, 2016.

BAUMAN, Z. Intimations of postmodernity. Londres: Routledge, 2003.

BRASIL. Lei n. 9.394, de 20 de dezembro 1996. Estabelece as diretrizes e bases da Educação Nacional. Diário Oficial da República

Federativa do Brasil, Poder Executivo, Brasília, DF, 23 dez. 1996. Disponível em: http://www.planalto.gov.br/ccivil 03/leis/L9394.htm. Acesso em: 14 nov. 2017.

BRASIL. Parâmetros Curriculares Nacionais: terceiro e quarto ciclos do ensino fundamental. Secretaria de Educação Fundamental: língua estrangeira. Brasília: MEC /SEF, 1998.

BRASIL. Lei $n^{\circ}$ 13.415, de 16 de fevereiro de 2017. Altera a Lei nº 9.394, de 20 de dezembro. Diário Oficial [da] República Federativa do Brasil, Brasília, 2017. Disponível em: http://www.planalto.gov.br/ccivil 03/ Ato2015-2018/2017/ Lei/L13415.htm . Acesso em: 14 nov. 2017.

COUPLAND, N. Style: language variation an identity. Cambridge: Cambridge University Press, 2007. 
DIAS, A. M. I. Discutindo caminhos para a indissociabilidade entre ensino, pesquisa e extensão. Revista Brasileira de Docência, Ensino e Pesquisa em Educação Física, Cristalina, v. 1, n. 1, p. 37-52, ago. 2009.

ECKERT, P. Jocks and burnouts: social categories and identity in the high school. New York: Teachers College Press, 1989.

Three waves of variation study: The emergence of meaning in the study of variation. Annual Review of Anthropology, n. 41, p. $87-100$, jun. 2012 .

. The meaning of style. In: CHIANG, W. F.; CHUN, E.; MAHALINGAPPA, L. \& MEHUS, S. (Ed.). Proceedings of the Eleventh Annual Symposium about Language and Society - Texas Linguistic Forum, v. 47, p. 41-53, 2004. Disponível em: http://salsa.ling.utexas.edu/proceedings/2003/eckert.pdf. Acesso em: 14 nov. 2017.

FABRO, M. F. Trajetórias de uma língua (mal) dita: supressão, legalidade e emergência do ensino da língua italiana nas escolas públicas de Santa Catarina. 2015. 532 f. Tese (Doutorado em Sociologia Política), Programa de Pós-Graduação em Sociologia Política, Universidade Federal de Santa Catarina, Florianópolis, 2015.

FREITAS, P. G. de; BALTHAZAR, L. L.; LUNATI, M. Dialetos e língua padrão: a educação linguística dos italianos em pátria e em contextos de imigração (1861-2015). Fórum Linguístico, Florianópolis, v. 12, n. 3, p. 755-770, 2015. Disponível em: https://periodicos.ufsc.br/index.php/forum/article/view/1984-8412.2015v12n3p755/30158. Acesso em: 18 out. 2016.

GAIO, M. L. M. Manutenção e perda das línguas e culturas italianas de Imigração no eixo Rio de Janeiro- Juiz de Fora . De volta ao futuro da língua portuguesa. In: SIMPÓSIO MUNDIAL DE ESTUDOS DE LÍNGUA PORTUGUESA , 5., 2017, Santarém. Atas...Simpósio 47 - Português do Brasil: História, contatos e variedades. Santarém, 2017, p. 1027-1040.

GUMPERZ, J. J.; COOK-GUMPERZ, J. Studying language, culture, and society: Sociolinguistics or linguistic anthropology? Journal of Sociolinguistics. v. 12, n. 4, p. 532-545, 2008.

HALL, S. A identidade cultural na pós-modernidade. 11. ed. Rio de Janeiro: DP\&A, 2005.

IRVINE, J. Style as distinctiveness: the culture and ideology of linguistic differentiation. In: ECKERT, P. ; RICKFORD, J. (Ed.). Style and sociolinguistic variation. Cambridge: Cambridge Press, 2001. p. 21-43.

KUMARAVADIVELU, B. Beyond methods: macrostrategies for language teaching. New Haven: Yale University Press, 2003.

Cultural pluralismo and its deceptions. In: Cultural globalization and language education. New Haven: Yale University, p. 95-116, 2008.

LANDULFO, C. Língua, material didático e formação de professores: questões refletidas para um ensino e aprendizagem de línguas mais consciente. In: MACHADO FILHO, A. V. L. (Org.). Língua, cultura e ensino: diálogos interdisciplinares. Salvador: EDUFBA, 2016. p. 63-78.

LEAL, J. Cultura e identidade açoriana: o movimento açorianista em Santa Catarina. Florianópolis: Insular, 2007.

LEFFA, V. J. O ensino de línguas estrangeiras no contexto nacional. Contexturas, APLIESP, n. 4, p. 13-24, 1999.

MAKONI, S. B. Sociolinguistics, colonial and postcolonial: an integrationist perspective. Language Sciences, v. 33, n. 4, p. 680-688, 2011. 
MAKONI, S.; MEINHOF, U. Linguística aplicada na África: desconstruindo a noção de língua. In: MOITA LOPES, L. P. da Paulo da (Org.). Por uma linguística aplicada indisciplinar. São Paulo: Parábola, 2006. p. 191-213.

MENDES, E. Língua, cultura e formação de professores: por uma abordagem de ensino intercultural. In: MENDES, E.; CASTRO, M. L. S. (Org.). Saberes em português: ensino e formação docente. Campinas: Pontes, 2008. p. 55-77.

MORELLO, R. Talian: protagonismo na luta pelo reconhecimento cultural e fortalecimento pela lei de cooficialização. Instituto de Investigação e Desenvolvimento em Política Linguística, 2015. Disponível em: http://e-ipol.org/talian-protagonismo-na-luta-peloreconhecimento-cultural-e-fortalecimento- pela-lei-de-cooficializacao/. Acesso em: 07 dez. 2017.

NOVA TRENTO. Histórico. Disponível em: https://www.novatrento.sc.gov.br/cms/pagina/ver/codMapaItem/37323. Acesso em: 23 nov. 2014.

ORTALE, F.; ZORZAN, F. J. de A. Mapeamento dos municípios com ensino de italiano em escolas públicas. Revista de Italianística XXVI, São Paulo, p. 121-144, 2013.

PAYER, M. A interdição da língua dos imigrantes (italianos) no Brasil: condições, modos, consequências. In: ORLANDI, Eni (Org.). História das idéias lingüísticas: construção do saber metalingüístico e constituição da língua nacional. Campinas, SP: Pontes/Unemat, 2001. p. 235-255.

PENNYCOOK, A. D. Uma Linguística Aplicada Transgressiva. In: MOITA LOPES, L. P. (Org.). Por uma Linguística Aplicada Indisciplinar. São Paulo: Parábola, 2006. p. 67-84.

RAJAGOPALAN, K. Política linguística: do que é que se trata, afinal. In: NICOLAIDES, C. et al. (Org.) Política e políticas linguísticas. Campinas: Pontes, 2013. p. 19-42.

RAMPTON, B. Continuidade e mudança nas visões de sociedade em linguística aplicada. In: MOITA LOPES, L. P. da (Org.). Por uma linguística aplicada indisciplinar. São Paulo: Parábola, 2006. p. 110-128.

RICKFORD, J. Concord and contrast in the characterization of the speech community. Sheffield Working Papers in Language and Linguistics. n. 3, 87-119, 1986.

SANTA CATARINA. Proposta Curricular de Santa Catarina: Formação Integral na Educação Básica. Florianópolis: SED, 2014.

SCHNEIDER, R. P. A instrução pública no Rio Grande do Sul (1770 - 1889). Porto Alegre: Ed. Universidade/UFRGS/EST edições, 1993.

SEVERO, C. G. A questão da identidade e o lócus da variação/mudança em diferentes abordagens sociolinguísticas. Revista Letra Magna, ano 4, n. 7, p. 1-152007.

SEVERO, C. G; MAKONI, S. B. Políticas linguísticas Brasil-África: por uma perspectiva crítica. Florianópolis: Insular, 2015. 
SILVA, G. F. S. da. Disponibilização de material teórico e didático para professores de língua estrangeira da rede pública de ensino de Santa Catarina: proposta de um espaço virtual na internet. 2003. 123 f. Dissertação (Mestrado em Engenharia de Produção) Programa de Pós-Graduação em Engenharia de Produção, Universidade Federal de Santa Catarina, Florianópolis, 2003.

SOUKUP, B. Speaker design in the context of southern american english: process models and empirical evidence. Brno Studeies in English, v. 37, n. 1, p. 125-138, 2011.

TRENTO, A. Do outro lado do Atlântico: um século de imigração italiana no Brasil. São Paulo: Nobel, 1989.

VALLE, C. R. M. Multifuncionalidade, mudança e variação de marcadores discursivos derivados de verbos cognitivos: forças semântico-pragmáticas, estilísticas e identitárias em competição. 2014. Tese (Doutorado em Linguística) - Programa de PósGraduação em Linguística, Universidade Federal de Santa Catarina, Florianópolis, 2014.

ZANINI, M. C. C. Italianidade no Brasil meridional: a construção da identidade étnica na região de Santa Maria-RS. Santa Maria, RS: Editora da UFSM, 2006.

\section{(ㄷ) (i) $(9)$}


ANEXO A: DADOS DE MATRÍCULAS NO ANO DE 2017 NA DISCIPLINA DE LÍNGUA ITALIANA OFERECIDA PELA REDE ESTADUAL,

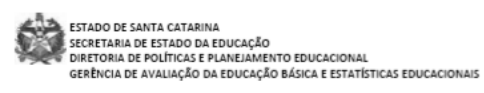

\begin{tabular}{|c|c|c|c|c|c|c|c|c|c|c|c|c|}
\hline \multirow{2}{*}{$\begin{array}{l}\text { Regional } \\
\text { SEARA }\end{array}$} & \multirow{2}{*}{ Municipio } & \multirow{2}{*}{ Cód SISGESC } & \multirow{2}{*}{\begin{tabular}{|l} 
Nome da UE \\
\end{tabular}} & \multirow{2}{*}{\begin{tabular}{|c|c|} 
& Nome do curso \\
\end{tabular}} & \multicolumn{7}{|c|}{ Número de matriculas na disciplina de Língua Estrangeira - Italiano } & \multirow{2}{*}{ TOTAL } \\
\hline & & & & & 6? Ano & 79 Ano & 89 Ano & 99 Ano & 1: Série & 2: Série & 3il Série & \\
\hline VIDEIRA & ARROIO TRINTA & 73210 & EEB GOV BORNHAUSEN & ENSINO FUNDAMENTAL - ANOS FINAIS & 14 & 12 & 16 & 19 & & & & 61 \\
\hline VIDERA & ARROIO TRINTA & 73210 & EEB GOV BORNHAUSEN & ENSINO MÉDIO & & & & & & & 10 & 10 \\
\hline VIDERA & ARROIO TRINTA & 73210 & EEB GOV BORNHAUSEN & ENSINO MÉDIO INOVADOR & & & & & 12 & 20 & 5 & 37 \\
\hline VIDERA & IOMERÉ & 73180 & EEB FRE EVARISTO & ENSINO MÉDIO & & & & & 12 & 4 & 8 & 24 \\
\hline Total Geral & & & & & 27 & 12 & 31 & 19 & 24 & 24 & 23 & 160 \\
\hline
\end{tabular}

Nota: Foram consideradas matriculas na disciplina curricular 322 - Lingua Estrangeira - Italiano.

Os professores lecionando a disciplina de Lingua Estrangeira Italiano curricular são efetivos no Estado de Santa Catarina. Total de professores: 3 :

Nota: Por ser um Sistema dinâmico considerar a data da fonte. 